\title{
Pulmonary Embolism Presenting with Evolving Electrocardiographic Abnormalities Mimicking Anteroseptal Myocardial Infarction: A Case Report
}

\author{
Necla Özer Hikmet Yorgun Uğur Canpolat Ahmet Hakan Ateş \\ Serdar Aksöyek \\ Department of Cardiology, Hacettepe University, Ankara, Turkey
}

\section{Key Words}

Myocardial infarction • Pulmonary thromboembolism •

Electrocardiography

\begin{abstract}
Objectives: To report a case with dynamic ST segment elevation suggestive of anteroseptal acute myocardial infarction (AMI) that proved to be bilateral pulmonary thromboembolism (PTE). Clinical Presentation and Intervention: A 50-year-old woman with syncope was transferred to the emergency department. Findings from the admission electrocardiogram were suggestive of anteroseptal AMI; however, coronary angiography revealed that the patient had normal coronary arteries. On further evaluation, the patient was found to have massive bilateral PTE. Conclusion: This report emphasizes the role of evolving electrocardiographic changes in the diagnosis of PTE, particularly in patients with chest pain and ST segment elevation suggestive of acute coronary syndrome.

Copyright $\odot 2011$ S. Karger AG, Basel
\end{abstract}

\section{Introduction}

The diagnosis of pulmonary thromboembolism (PTE) with changes shown by electrocardiography (ECG) is a challenge in the clinical practice due to rare pathognomonic findings. Although several ECG changes can be observed in the acute phase of PTE, ST segment elevation is a rare occasion [1-3]. This report describes a woman who showed dynamic ST segment elevation suggestive of anteroseptal acute myocardial infarction (AMI).

\section{Case Report}

A 50-year-old woman was admitted to the emergency department with shortness of breath and epigastric pain radiating to the back and syncopal attack while waiting in the hospital for a control visit. She recovered spontaneously and felt epigastric pain thereafter. She had been injured after a traffic accident 2 weeks previously with fractures of the right scapula and 4th-9th ribs and had been discharged from hospital without surgical intervention. The patient's medical history was significant for diabetes mellitus and hypertension of 10 years. Her prescribed medications included insulin and ramipril. The family history was unremarkable. On admission her pulse rate was regular $(100 / \mathrm{min})$, blood pressure was $100 / 65 \mathrm{~mm} \mathrm{Hg}$ and tachypneic with a respiratory rate of 24 breaths/min. Physical examination revealed rales

\begin{tabular}{ll}
\hline KARGER & (c) 2011 S. Karger AG, Basel \\
Fax $+41613061234-7571 / 11 / 0206-0577 \$ 38.00 / 0$ \\
$\begin{array}{l}\text { E-Mail karger@karger.ch } \\
\text { www.karger.com }\end{array}$ & $\begin{array}{l}\text { Accessible online at: } \\
\text { www.karger.com } / \mathrm{mpp}\end{array}$
\end{tabular}



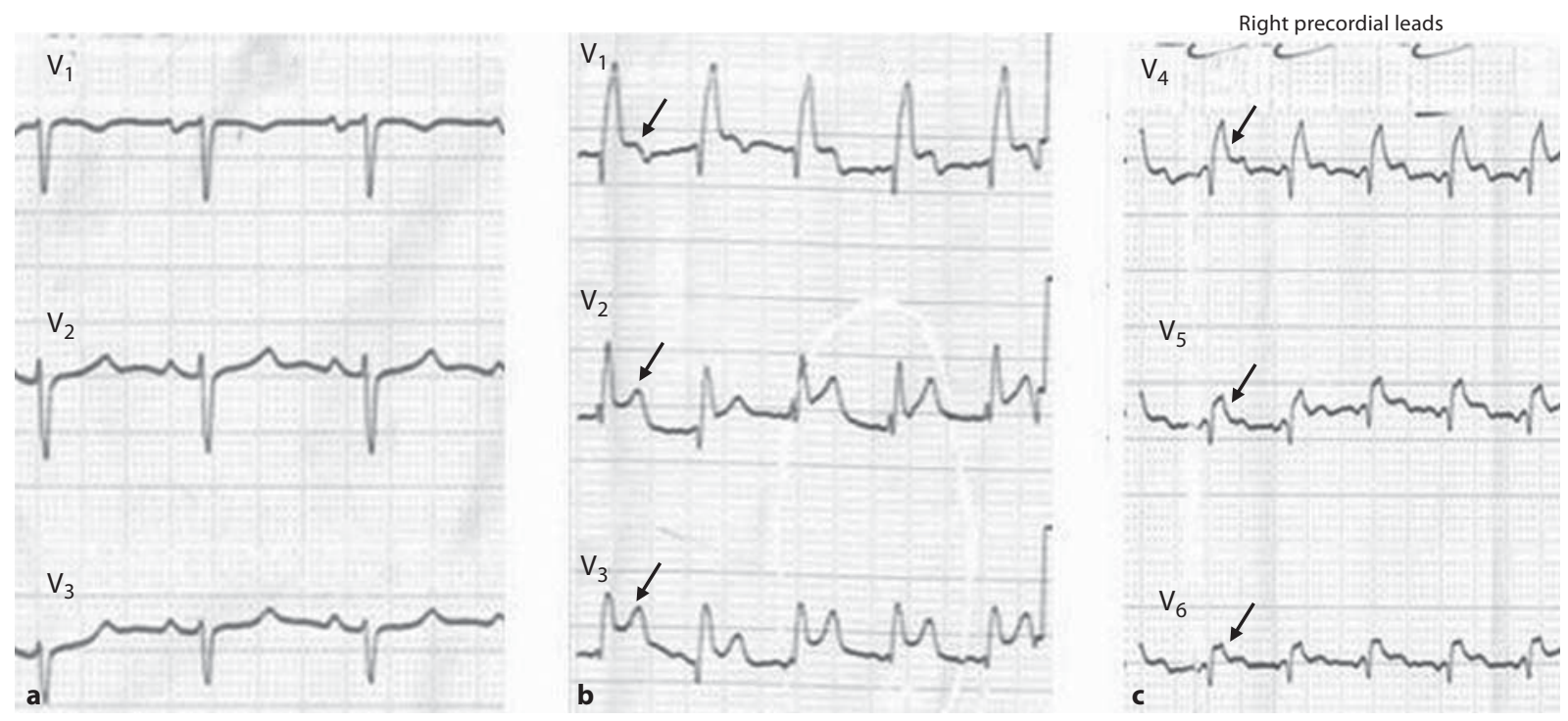

Fig. 1. a Initial ECG of the patient showing sinus rhythm 2 weeks before PTE. b ECG performed $1 \mathrm{~h}$ after admission demonstrating ST segment elevation in the $\mathrm{V}_{1-3}$ leads consistent with anteroseptal AMI. c Right-sided precordial leads showing ST segment elevation in $\mathrm{V}_{4-6} \mathrm{R}$.

on the right lower lobe of lung and a 2/6 systolic murmur in the mesocardiac area. Complete blood count, cardiac troponins and blood chemistry were within normal limits except the serum glucose level indicating hyperglycemia $(270 \mathrm{mg} / \mathrm{dl})$. Initial arterial blood gas analysis revealed a $\mathrm{pH}$ of 7.51, an oxygen pressure of $65 \mathrm{~mm} \mathrm{Hg}$, carbon dioxide pressure of $36 \mathrm{~mm} \mathrm{Hg}$, oxygen saturation of $90 \%$ and a bicarbonate concentration of $24 \mathrm{mmol} / \mathrm{l}$. The electrocardiogram of the patient had been in sinus rhythm without right bundle branch block (RBBB) 2 weeks previously (fig. 1a). ECG showed sinus tachycardia (112/min), RBBB with ST segment elevation on precordial leads $\mathrm{V}_{1-3}$ and DII, DIII, aVF and reciprocal changes in DI and aVL (fig. 1b). Right precordial leads revealed ST segment elevations $(2 \mathrm{~mm})$ and $\mathrm{q}$ waves $(2 \mathrm{~mm})$ in $\mathrm{V}_{4-6} \mathrm{R}$ (fig. 1c). As a result, therapy for acute coronary syndrome was initiated (aspirin, clopidogrel, unfractionated heparin, atorvastatin), and arrangements were made for emergency coronary angiography for suspected acute coronary occlusion; however, the coronary angiogram revealed normal coronary arteries. During the course an atrial tachycardia with a ventricular rate of $164 / \mathrm{min}$ was observed, and afterwards sinus tachycardia resumed spontaneously. After cardiac catheterization, transthoracic echocardiography revealed right ventricular dilatation, severe tricuspid insufficiency, pulmonary hypertension $(60 \mathrm{~mm} \mathrm{Hg})$ and displacement of the interventricular septum into the left ventricle; however, left ventricular systolic function was normal. Also, the patient demonstrated 'McConnell's sign', which is known as ventricular freewall hypokinesia with preservation of right ventricular apical motion and was reported in case of massive PTE [4]. Multidetector computed tomography pulmonary angiography (Somatom Definition, Siemens, Erlangen, Germany) showed bilateral pulmonary arterial thrombus with dilated right ventricle and displaced interventricular septum into the left side, but lower extremity venography did not show any finding compatible with deep venous thrombosis. Intravenous heparin was resumed by an infusion of $1,000 \mathrm{U} / \mathrm{h}$, and the infusion was adjusted according to a previously established activated thromboplastin time. In the second hour of unfractionated heparin infusion, the patient was stabilized, felt better and ECG showed sinus rhythm with RBBB without ST segment elevation (fig. 2a). Twenty-four-hour ECG revealed sinus rhythm, and RBBB disappeared with ST segment depression in $\mathrm{V}_{1-3}$, consistent with a right ventricular strain pattern (fig. 2b). The remaining hospital stay of the patient was uneventful. Anticoagulation with warfarin was initiated before discharge from the hospital; the patient is doing well at 1 month of followup.

\section{Discussion}

The nonspecific ST segment and T wave changes in the ECG of this case were similar to those of previous reports [5-12]. ECG changes are generally of abrupt onset and transient in character due to the progression of embolism. Sreeram et al. [6] investigated the ECG changes 

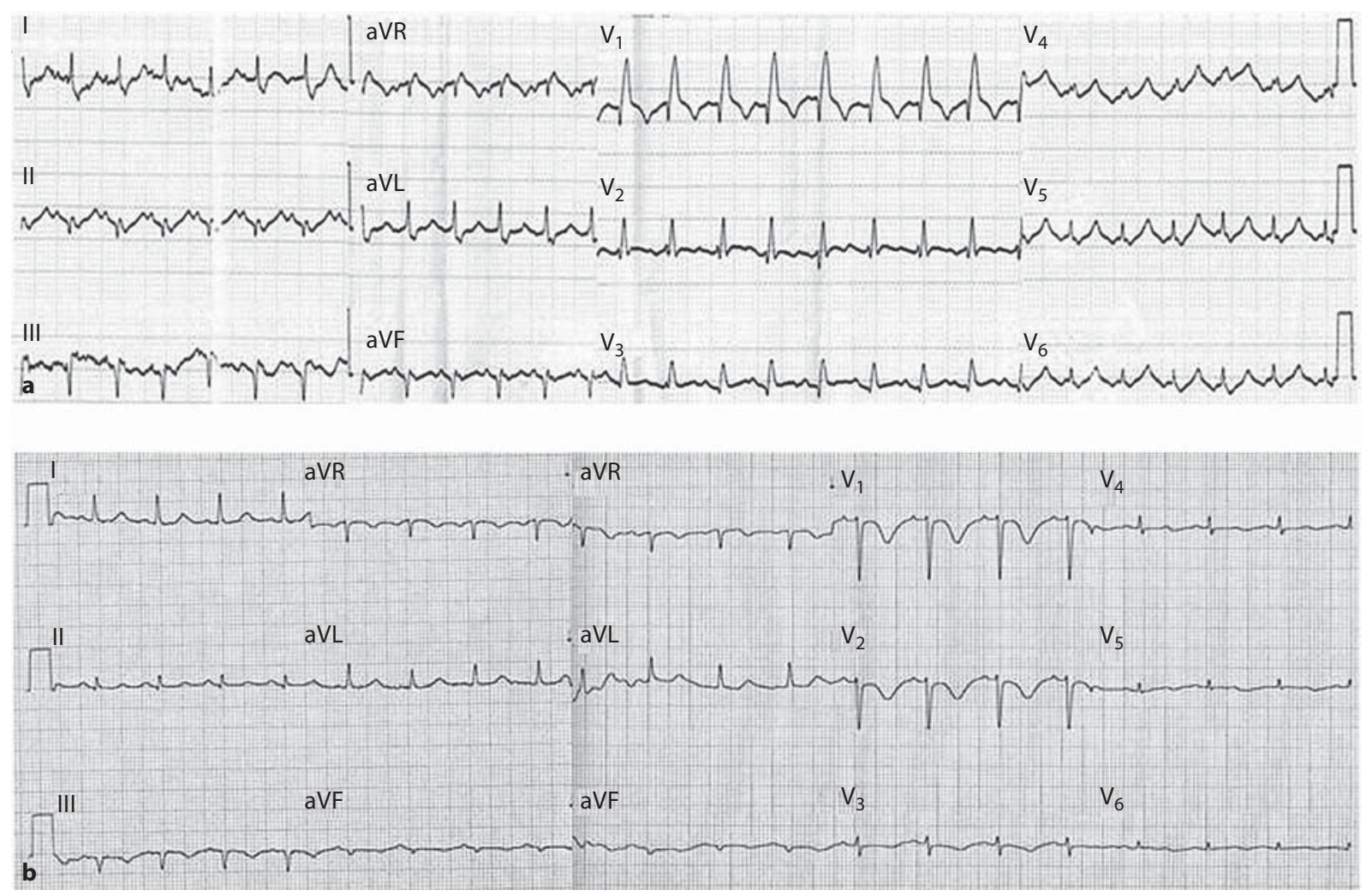

Fig. 2. a ECG $24 \mathrm{~h}$ after admission, normalization of ST segment elevations. b ECG before discharge from hospital with resolved RBBB but ST segment depression in $\mathrm{V}_{1-3}$, consistent with a right ventricular strain pattern.

in PTE and suggested that the diagnosis of PTE could be made on the basis of several ECG abnormalities including an $S_{1} Q_{3} T_{3}$ pattern, qr pattern in $V_{1}$, rSr' pattern in leads $\mathrm{V}_{1-2}, \mathrm{rS}$ pattern in leads $\mathrm{V}_{3-5}$, $\mathrm{T}$ wave inversion in leads $\mathrm{V}_{1-5}$, ST segment elevation in leads $\mathrm{V}_{1-3}$ and $\mathrm{ST}$ segment depression in lead D1 in the majority of conditions. A pseudoinfarction pattern occurs in $3-11 \%$ with acute PTE $[5,7]$. Also Lynch et al. [8] analyzed 115 patients with acute PTE and concluded that left axis deviation $\left(\leq 30^{\circ}\right)$ at the time of acute PTE was twice as frequent as right axis deviation. Other reported findings were right axis deviation, leftward displacement of the transitional zone, p pulmonale and atrial dysrhythmias including atrial fibrillation, atrial flutter, atrial tachycardia and premature atrial beats [5]. Additionally, ECG findings in the rightsided precordial leads in acute PTE have been rarely documented previously. Slurring of the ascending limb of the
$S$ wave in leads $V_{4} R$ and $V_{1-2}$ was shown in a previous report [9]. Chia et al. [10] described ECG findings of ST segment elevation and a qs or qr pattern in 3 of 4 patients with PTE in leads $\mathrm{V}_{4-6} \mathrm{R}$ similar to the findings of Akula et al. [11] in which the ST segment elevation was greater than $1 \mathrm{~mm}$ and depths of the $q$ waves in leads $V_{4-6} R$ were 1.5-4 $\mathrm{mm}$; those abnormalities were mostly normalized within 6 weeks due to the transient nature of ECG abnormalities. Tan et al. [12] and Andersen et al. [13] found that ST segment elevation was smaller than $0.5 \mathrm{~mm}$ and $\mathrm{q}$ wave depth varied between 0.5 and $1.5 \mathrm{~mm}$ in normal subjects.

Although ST segment elevation with the complaint of chest pain made us to focus on acute coronary syndrome initially, the diagnosis of acute PTE was also considered because besides the recent history of trauma and reduced mobility, several ECG abnormalities are also compatible 
with PTE. A new-onset RBBB that had not been present 2 weeks previously and the initial ECG showing sinus tachycardia are the most common findings in PTE, but can also be seen in acute coronary syndrome; right precordial leads revealed ST segment elevations $(2 \mathrm{~mm})$ and $\mathrm{q}$ waves $(2 \mathrm{~mm})$ in $\mathrm{V}_{4-6} \mathrm{R}$, an abnormal finding reported in PTE, previously. Third, atrial tachycardia evolved during the course, an atrial rhythm abnormality seen in PTE. Fourth, after unfractionated heparin infusion, synchronous with symptomatic recovery, ST segment depression and recovery of sinus rhythm were observed. Fifth, ST segment depression in $\mathrm{V}_{1-3}$ was seen in ECG with the resolution of RBBB before the discharge.

Due to the presence of atypical ECG changes for acute PTE in our patient, AMI was considered initially in the differential diagnosis, and a coronary angiogram was performed before other noninvasive tests. Other evaluations like echocardiography could be helpful in this case. Transthoracic echocardiography is a readily available bedside test that can be performed in the emergency department on admission and is helpful to differentiate massive PTE and anteroseptal AMI, but rarely provides direct visualization of PTE. The echocardiography was performed on our patient after a coronary angiogram that was consistent with massive PTE. If echocardigraphy had been performed immediately, coronary angiography could have been avoided in our patient.

\section{Conclusion}

This case emphasized the rare association of PTE with ST segment elevation, especially in the anteroseptal derivations. This case also showed the usefulness of the echocardiogram in differentiating AMI from massive PTE. Therefore, we recommend that physicians should remember the presence of PTE in patients with chest pain or dyspnea, even when ECG points to AMI.

\section{References}

$>1$ Livaditis IG, Paraschos M, Dimopoulos K: Massive pulmonary embolism with ST elevation in leads $\mathrm{V}_{1}-\mathrm{V}_{3}$ and successful thrombolysis with tenecteplase. Heart 2004;90:e41.

$\checkmark 2$ Falterman TJ, Martinez JA, Daberkow D, Weiss LD: Pulmonary embolism with ST segment elevation in leads $V_{1}$ to $V_{4}$ : case report and review of the literature regarding electrocardiographic changes in acute pulmonary embolism. J Emerg Med 2001;21: 255-261.

$>3$ Fasullo S, Paterna S, Di Pasquale P: An unusual presentation of massive pulmonary embolism mimicking septal acute myocardial infarction treated with tenecteplase. J Thromb Thrombolysis 2009;27:215-219.

$\checkmark 4$ McConnell MV, Solomon SD, Rayan ME, Come PC, Goldhaber SZ, Lee RT: Regional right ventricular dysfunction detected by echocardiography in acute pulmonary embolism. Am J Cardiol 1996;78:469-473.
5 Stein PD, Dalen JE, McIntyre KM, Sasahara AA, Wenger NK, Willis PW 3rd: The electrocardiogram in acute pulmonary embolism. Prog Cardiovasc Dis 1975;17:247-257.

-6 Sreeram N, Cheriex EC, Smeets JL, Gorgels AP, Wellens HJ: Value of the 12-lead electrocardiogram at hospital admission in the diagnosis of pulmonary embolism. Am J Cardiol 1994;73:298-303.

7 Romhilt D, Susilavorn B, Chou TC: Unusual electrocardiographic manifestation of pulmonary embolism. Am Heart J 1970;80:237241.

$>8$ Lynch RE, Stein PD, Bruce TA: Leftward shift of frontal plane QRS axis as a frequent manifestation of acute pulmonary embolism. Chest 1972;61:443-446.
9 Smith M, Ray CT: Electrocardiographic signs of early right ventricular enlargement in acute pulmonary embolism. Chest 1970; 58:205-212.

10 Chia BL, Tan HC, Lim YT: Right sided chest lead electrocardiographic abnormalities in acute pulmonary embolism. Int J Cardiol 1997;61:43-46.

11 Akula R, Hasan SP, Alhassen M, Mujahid H, Amegashie E: Right-sided EKG in pulmonary embolism. J Natl Med Assoc 2003;95: 714-717.

12 Tan CC, Hiew TM, Chia BL: Right chest electrocardiographic patterns in normal subjects. Chest 1990;97:572-575.

13 Andersen HR, Nielsen D, Hansen LG: The normal right chest electrocardiogram. J Electrocardiol 1987;20:27-32. 